\title{
Drugs to block cytokine signaling for the prevention and treatment of inflammation-induced preterm birth
}

\section{Pearl Y. $\mathrm{Ng}^{\dagger}$, Demelza J. Ireland ${ }^{*}{ }^{\dagger}$ and Jeffrey A. Keelan}

King Edward Memorial Hospital, School of Women's and Infants' Health, University of Western Australia, Perth, WA, Australia

Edited by:

Masaaki Murakami, Hokkaido

University, Japan

\section{Reviewed by:}

Hideki Ogura, Yale University, USA

Yasunobu Arima, Osaka University, Japan

\section{*Correspondence}

Demelza J. Ireland, King Edward

Memorial Hospital, School of

Women's and Infants' Health,

University of Western Australia, 374

Bagot Road, Subiaco, Perth, WA

6008, Australia

e-mail: demelza.ireland@uwa.edu.au

${ }^{\dagger}$ Pearl Y. Ng and Demelza J. Ireland

have contributed equally to this work.
Preterm birth (PTB) at less than 37 weeks of gestation is the leading cause of neonatal morbidity and mortality. Intrauterine infection (IUI) due to microbial invasion of the amniotic cavity is the leading cause of early PTB ( $<32$ weeks). Commensal genital tract Ureaplasma and Mycoplasma species, as well as Gram-positive and Gram-negative bacteria, have been associated with IUI-induced PTB. Bacterial activation of Toll-like receptors and other pattern recognition receptors initiates a cascade of inflammatory signaling via the NF-kB and p38 mitogen-activated protein kinase (MAPK) signaling pathways, prematurely activating parturition. Antenatal antibiotic treatment has had limited success in preventing PTB or fetal inflammation. Administration of anti-inflammatory drugs with antibiotics could be a viable therapeutic option to prevent PTB and fetal complications in women at risk of IUI and inflammation. In this mini-review, we will discuss the potential for anti-inflammatory drugs in obstetric care, focusing on the class of drugs termed "cytokine suppressive anti-inflammatory drugs" or CSAIDs. These inhibitors work by specifically targeting the NF-KB and p38 MAPK inflammatory signaling pathways. Several CSAIDs are discussed, together with clinical and toxicological considerations associated with the administration of anti-inflammatory agents in pregnancy.

Keywords: chorioamnionitis, cytokine suppressive anti-inflammatory drugs, intrauterine inflammation, intrauterine infection, NF-kB inhibitors, preterm birth

\section{INTRODUCTION}

Preterm birth (PTB), delivery prior to 37 weeks of gestation, is estimated to affect $5-15 \%$ of pregnancies worldwide (1) and remains the leading cause of morbidity and mortality of neonates (2) and the second largest direct cause of death in children under 5 years (3). There are many pathological pathways which can lead to PTB, including intrauterine infection (IUI), uterine ischemia, uterine over-distension, abnormal allogeneic recognition and allergic reactions, cervical disease, and endocrine disorders (4). Whilst interventions such as progesterone therapy and ultrasound cervical monitoring are now utilized in many high-risk clinics in developed countries, they are not specific to a particular PTB etiology (5). IUI and inflammation has been casually linked to early PTB and account for approximately $40 \%$ of all spontaneous PTB $(6,7)$. Microbial invasion of the amniotic cavity, most commonly with ascending vaginal microorganisms, activates pattern

Abbreviations: ATP, adenosine triphosphate; COX, cyclooxygenase; CSAID, cytokine suppressive anti-inflammatory drug; FIRS, fetal inflammatory response syndrome; IкB, inhibitor of NF-кB; IKK, IкB kinase; IL, interleukin; IRAK, IL1R-associated kinase; IUI, intrauterine infection; LPS, lipopolysaccharide; MAPK, mitogen-activated protein kinase; MCP, monocyte chemoattractant protein; MKK, MAPK kinase; MMP, matrix metalloproteinase; NAC, $N$-acetyl cysteine; NBDI,

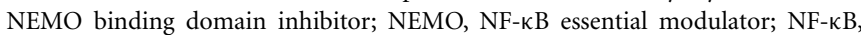
nuclear factor $\kappa \mathrm{B}$; NSAID, non-steroidal anti-inflammatory drug; OxZnl, 5z-7oxozeaenol; PAMP, pathogen-associated molecular pattern; PTB, preterm birth; PTL, preterm labor; PG, prostaglandin; SSZ, sulfasalazine; TAK, TGF $\beta$ activated kinase; TGF, transforming growth factor; TLR, Toll-like receptor; TNF, tumor necrosis factor; TRAF, TNF receptor-associated factor. recognition receptors (PRRs) which induce the production of pro-inflammatory mediators leading to the premature activation of labor and ultimately PTB [reviewed in Ref. (8)]. Neonatal health and development is further compromised if chronic exposure of the fetus to these inflammatory mediators results in fetal inflammatory response syndrome (FIRS) $(9,10)$. It is likely that optimal pregnancy outcomes will come from the development of therapeutic strategies that are cause-specific and targeted to women at risk and likely to benefit from the treatment.

There is growing interest in therapeutic interventions that target the inflammatory labor cascade by blocking the production of pro-inflammatory mediators or up-regulating antiinflammatory mediators and/or the exogenous administration of anti-inflammatory or pro-resolution mediators. In their review of anti-inflammatory agents for the prevention of labor, Rinaldi et al. (8) concluded that progesterone was the most likely compound to progress into mainstream clinical use. Although progesterone treatment reduces the incidence of preterm delivery (11), its ability to block inflammatory signaling associated with infection is unclear. In a previous review, we concluded that while the use of anti-inflammatory agents for the treatment and/or prevention of PTB appears promising, pre-clinical studies demonstrating clear benefits and lack of toxicity are needed (12). This mini-review will revisit the benefits and risks of administration of anti-inflammatory drugs in obstetric care, focusing specifically on the emerging class of drugs termed "cytokine suppressive anti-inflammatory drugs" or CSAIDs. These inhibitors, when administered in conjunction with an effective antibiotic regimen, 
have the potential to both prolong pregnancy and improve neonatal outcomes.

\section{INTRAUTERINE INFECTION AND INFLAMMATION}

One in four preterm infants is born to a mother with IUI (13). These infections commonly arise via the ascending route of infection where bacteria from the cervicovaginal fluid ascend, breach the cervical barrier, colonize the amniotic fluid, and invade fetal membranes and in some cases the fetus (14). IUI also occurs via hematogenous dissemination with trans-placental transfer (15). Chorioamnionitis is the hallmark feature of IUI and is typically diagnosed after delivery by histopathology as the infiltration of leukocytes into the fetal membranes; histological chorioamnionitis severity is positively correlated with intra-amniotic infection, fetal inflammation, and poorer pregnancy outcomes $(16,17)$. While bacteria are the major organism responsible for chorioamnionitis, viruses and yeast are also capable of causing intrauterine inflammation.

Genital Mycoplasma and Ureaplasma species are some of the most commonly isolated organisms from amniotic fluid in cases of infection-induced PTB (7), although the appearance of these, and numerous other bacteria $(7,18)$, in amniotic fluid does not necessarily denote causation (19). Evidence suggests that the extent of bacterial colonization, route of infection, and the stimulatory capacity of the bacteria all play key roles in the activation of maternal and fetal pro-inflammatory signaling cascades which induce production of pro-inflammatory cytokines (e.g., IL- $1 \beta$ and TNF- $\alpha$ ) and chemokines (e.g., IL-8 and MCP-1), which in turn promote prostaglandin (PG) production and myometrial contractility, ripening of the cervix, and degradation of the fetal membrane extracellular matrix leading to preterm labor (PTL) (20). The importance of cytokine and chemokine signaling in the pathogenesis of infection-induced PTL is well established and has been thoroughly reviewed in Ref. $(14,21,22)$. Microorganism-specific pathogen-associated molecular patterns (PAMPs) are sensed by trans-membrane PRRs, e.g., Toll-like receptors (TLRs) $(23,24)$, with ligation resulting in recruitment of adaptor proteins [IL-1Rassociated kinase (IRAK)1, IRAK4, and TNF receptor-associated factor (TRAF6)] and activation of TAK1 kinase (Figure 1). TAK1 then mediates the phosphorylation and activation of the IКB kinase complex (IKK), which comprises of two catalytic subunits (IKK $\beta$ and IKK $\alpha$ ) and a regulatory subunit IKK $\gamma$ (25). The IKK complex phosphorylates I $\mathrm{B}-\alpha$, targeting it for degradation, allowing NF- $\kappa \mathrm{B}$ heterodimers to dissociate and translocate to the nucleus to drive inflammatory gene expression (26). TAK1 kinase can also phosphorylate and activate the mitogen-activated protein kinases (MAPKs), MKK3 and MKK6 that subsequently activate p38 MAPK (27). Although there is some evidence that p38 MAPK is involved in intrauterine inflammatory activation of fetal membranes (28), the exact mechanism of activation in gestational tissues and pregnancy is unknown and likely varies according to the nature of the stimulatory agent.

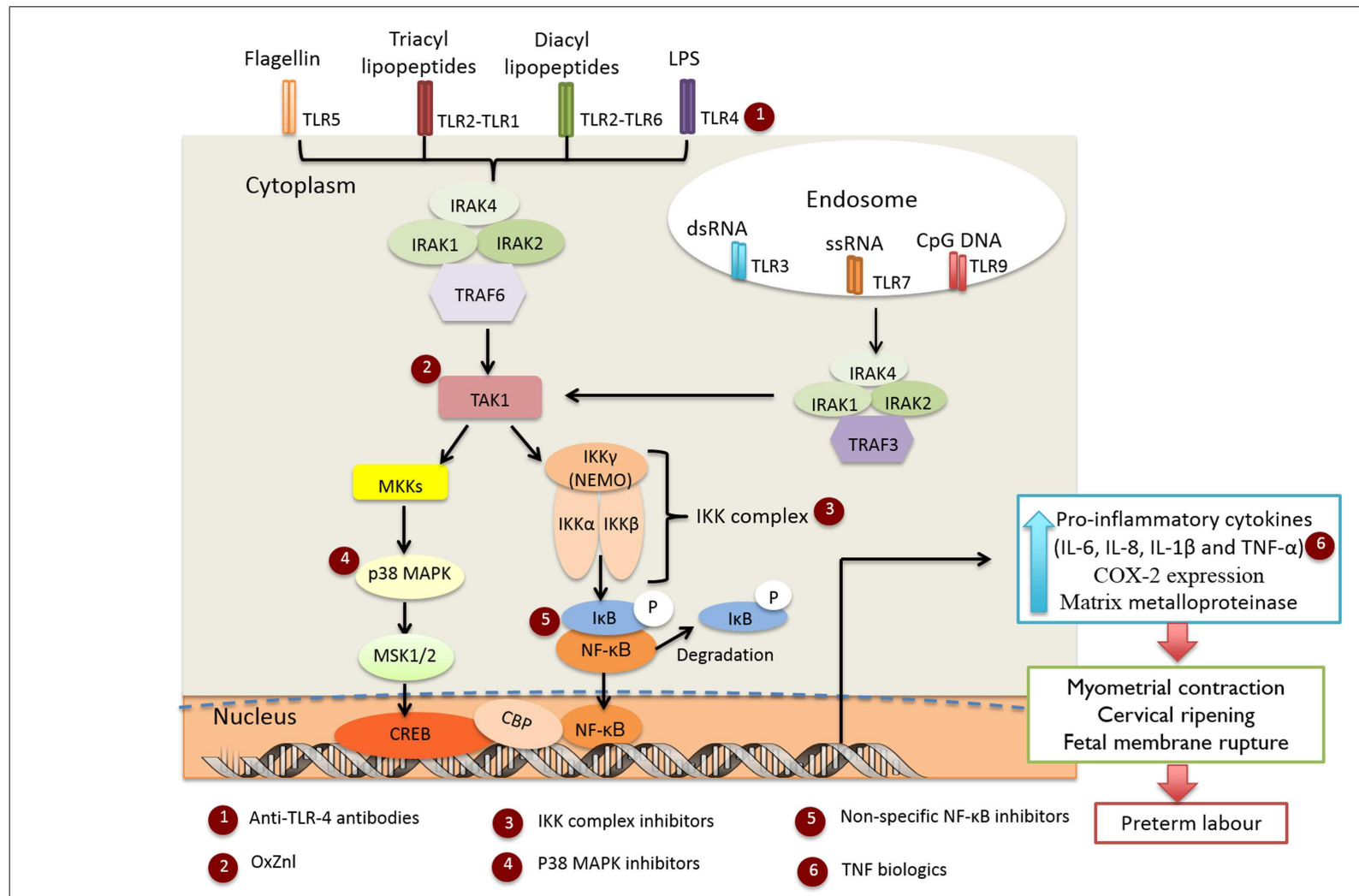

FIGURE 1 | Infection-induced preterm labor triggered by activation of TLR-mediated NF-kB and p38 MAPK inflammatory signaling cascades. Targets for the selected anti-inflammatory agents are indicated in red circles. 


\section{TARGETING PRO-INFLAMMATORY SIGNALING FOR PREVENTION OR TREATMENT OF PTB}

Antibiotic treatment is routinely given to women presenting with PTL $(29,30)$. However, it is not the infection but the subsequent inflammation that initiates PTL and is primarily responsible for adverse neonatal outcomes. The use of non-steroidal antiinflammatory drugs (NSAIDs) to inhibit PG synthesis provided initial evidence that the use of anti-inflammatory drugs may help to delay PTB $(31,32)$. However, significant pregnancy complications and adverse fetal side effects have been associated with their use (33) as summarized in Table S1 in Supplementary Material. The following sections consider a number of promising alternative anti-inflammatory agents with potential for use in preventing inflammation-driven PTB.

\section{NON-SPECIFIC NF-KB INHIBITORS}

$N$-acetyl cysteine (NAC) is a non-specific free radical scavenger and NF- $\kappa$ B inhibitor (34-36) (Figure 1, indicated by red circle at position 5). Treatment of fetal membranes with NAC has been shown to inhibit lipopolysaccharide (LPS) and $\gamma$-irradiation killed E. coli-induced inflammation $(37,38)$. NAC has been tested clinically in pregnancy, but has not progressed into mainstream clinical use (39) and the clinical findings have not yet been replicated in other studies. Sulfasalazine (SSZ), a salicylate drug that blocks NF$\kappa \mathrm{B}$ activation by directly inhibiting the IKK kinases (40), is well tolerated and approved for use in pregnancy, with no discernible increase in risk of fetal congenital defects, morbidity, or mortality (41). SSZ treatment has been shown to reduce both LPS-induced placental inflammation in an explant model (42), and the incidence of preterm delivery in a mouse model of PTL (43). However, increased levels of chorionic apoptosis has also been reported in a human membrane model after SSZ exposure $(20 \mathrm{~h})$, suggesting that prolonged treatment may result in eventual membrane degradation and loss of function and structural integrity (42).

\section{TLR4 ANTAGONISTS}

TLR4 activation by LPS is the most commonly used IUI model and accordingly TLR4 antagonism has been assessed for therapeutic potential (Figure 1, red circle at position 1). Studies of TLR4-LPS inhibition using a monoclonal anti-TLR4 antibody found treatment effective in vivo in reducing pro-inflammatory mediator (TNF- $\alpha$, IL-8, and PGE 2 ) production in amniotic fluid (44), and the incidence of LPS-induced PTB (45). Alternate TLR4 antagonists include eritoran tetrasodium (46) and TAK-242 (47), neither of which have been examined in this context. IUI and inflammation can be triggered by a range of PAMPs, while TLR4 antagonism is only appropriate in cases of Gram-negative bacteria-induced PTL.

\section{TNF- $\alpha$ BIOLOGICS}

Conflicting reports exist regarding the efficacy of anti-TNF- $\alpha$ antibodies to decrease the incidence of PTB in murine models (48, $49)$. Drugs blocking the production of pro-inflammatory TNF$\alpha$ are used in pregnancy $(50,51)$, but the complexity of cytokine interactions associated with PTL suggests that targeting individual cytokines may not be the most optimal therapeutic intervention (Figure 1, red circle at position 6). Interestingly, clinical studies have reported that maternal administration of antibody-based
TNF- $\alpha$ biologics (e.g., infliximab) persist in the neonatal circulation for many weeks after birth (52) and may therefore dampen both intrauterine and fetal inflammation protecting the fetus from the adverse sequelae of IUI and inflammation. There is little evidence for congenital abnormalities with the use of anti-TNF- $\alpha$ therapy during pregnancy (53), but high levels in fetal circulation may increase risk of neonatal infection. The consequences of such treatments for the developing immune system need to be fully considered.

\section{CSAIDS: A NOVEL CLASS OF ANTI-INFLAMMATORY DRUGS}

As a class of compounds, CSAIDs specifically target the NF-кB and p38 MAPK signaling pathways to inhibit cytokine-mediated events with demonstrated efficacy in a range of animal models (54-56). These agents are now being examined for their potential to be more effective and selective than NSAIDs for the inhibition of inflammation-driven PTB, as they directly target signaling molecules leading to the activation of the NF- $\kappa \mathrm{B}$ and p38 MAPK inflammatory cascades without interfering with the constitutive/homeostatic roles of prostanoids (Table 1 and Figure 1). Importantly, depending on the route of administration and placental transfer properties, CSAIDs may have the potential to block intra-amniotic and fetal inflammation, thereby protecting the fetus from the adverse sequelae of exposure to inflammatory mediators.

\section{p38 MAPK inhibitors}

The first p38MAPK inhibitor investigated in human extraplacental membranes was SKF-86002, a potent inhibitor of p38 MAPK and less potent inhibitor of cyclooxygenase-2 (COX-2) and 5lipoxygenase activity (75). This led to research into the use of similar inhibitors, which selectively bind to the adenosine triphosphate (ATP) site of p38 MAPK, to block the placental production of pro-inflammatory cytokines (Figure 1, red circle at position 4). Lappas et al. (28) reported that treatment of LPS-stimulated human fetal membranes with SB202190 inhibited the release of IL-6, TNF- $\alpha$, and PGs, whilst we demonstrated that SB239063 inhibited the production of IL- 6 , TNF- $\alpha$, and $\mathrm{PGE}_{2}$ at both the maternal and fetal faces of human fetal membranes stimulated with $\gamma$-irradiation-killed E. coli (38). This suggested that p38 MAPK may be a useful pharmacological target for prevention of PTL; however, caution is warranted as MAPKs are also involved in many aspects of cell function and signaling, including placental growth and differentiation $(59,60)$.

\section{IKK complex inhibitors}

A short, membrane-permeable NEMO-binding domain inhibitor (NBDI) peptide that spans the IKK $\beta$ NEMO-binding domain disrupting interaction between NEMO and IKK $\beta$ (76) (Figure 1, red circle at position 3 ), is effective in ameliorating inflammatory responses in ear swelling (77) and colitis (63) mouse models. Recently, NBDI was also shown to inhibit LPS and Ureaplasma parvum-induced $\mathrm{PGE}_{2}$ production in ovine gestational membranes (38) but not $\gamma$-irradiation-killed E. coli-induced proinflammatory responses in ex vivo human fetal membranes (38); differences in binding affinity or endogenous protease activity in human fetal membranes may explain differential efficacy observed. 
Table 1 | Cytokine suppressive anti-inflammatory drugs (CSAIDs) with potential for the prevention or treatment of PTB

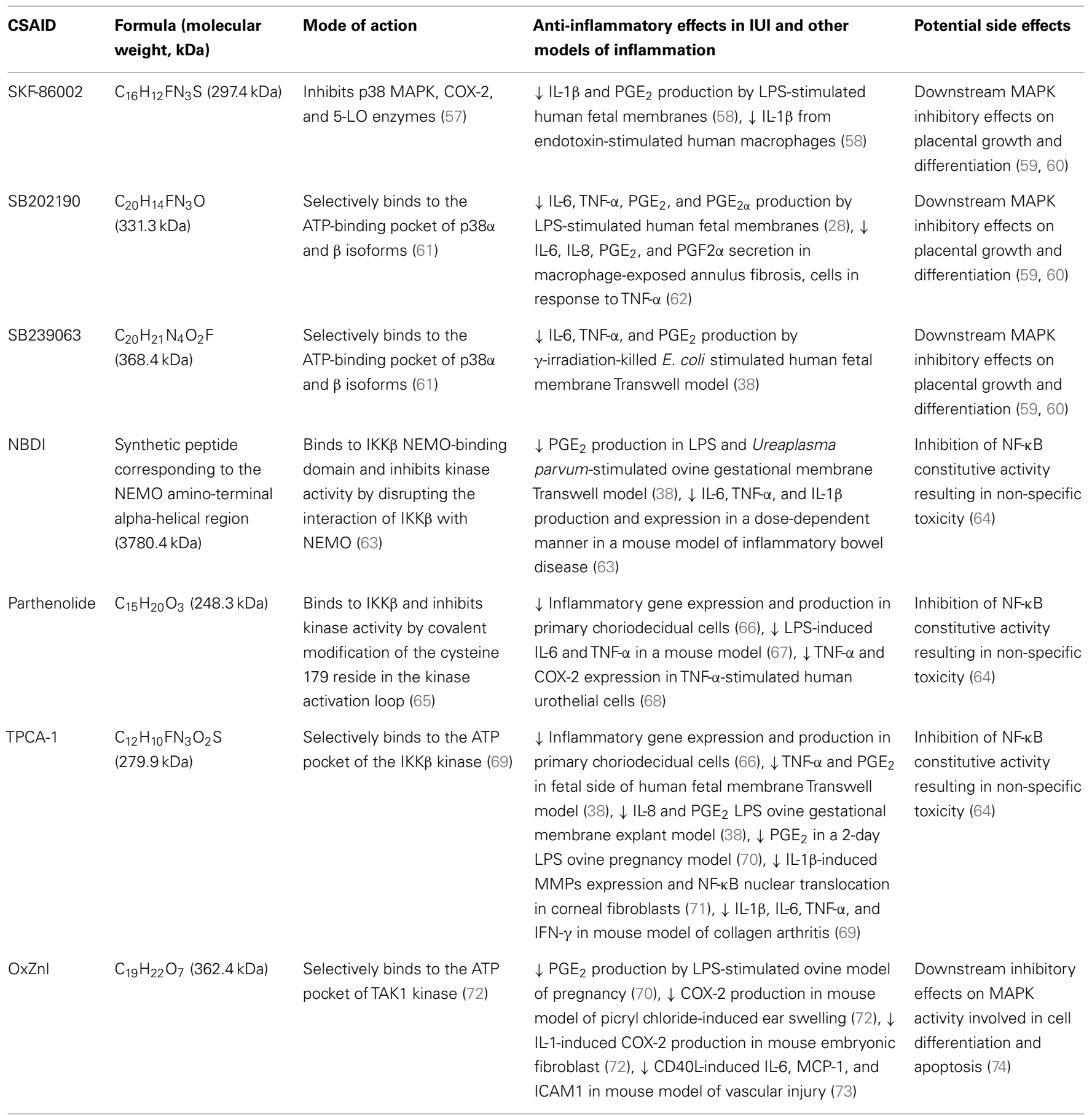

OxZnl, 5z-7-oxozeaenol; ATP, adenosine triphosphate; COX, cyclooxygenase; CSAID, cytokine suppressive anti-inflammatory drug; IFN, interferon; IL, interleukin; IUI, intrauterine infection; IKK, IKB kinase; LPS, lipopolysaccharide; MMP, matrix metalloproteinase; MAPK, mitogen-activated protein kinase; MCP, monocyte chemoattractant protein; NBDI, NEMO-binding domain inhibitor; NEMO, NF-KB essential modulator; NF-KB, nuclear factor $\kappa B$; $P G$, prostaglandin; TAK, TGFB-activated kinase; TNF, tumor necrosis factor.

TPCA-1 (69) and parthenolide (65) are specific IKK $\beta$ inhibitors (Figure 1, red circle at position 3) shown to inhibit LPS-induced inflammation and NF-KB nuclear translocation in primary choriodecidual cells (66). Unlike SSZ, no impairment of cell viability, apoptosis, or expression of anti-apoptotic genes was detected in these studies (66). Addition of TPCA-1 to the fetal compartment of a human fetal membrane Transwell model was also reported to inhibit $\gamma$-irradiation-killed E. coli-induced TNF- $\alpha$ and $\mathrm{PGE}_{2}$ production in the fetal compartment, and to a lesser extent in the maternal compartment (38). TPCA-1 also blocked LPS- and $U$. 
parvum-induced IL- 8 and $\mathrm{PGE}_{2}$ production in an ovine gestational membrane model (38), demonstrating that this pharmacological strategy is likely to work across a wide range of microbial stimuli and different PAMPs. Significantly, in an ovine model of LPS-induced chorioamnionitis, intra-amniotic administration of TPCA-1 was found to inhibit production and accumulation of $\mathrm{PGE}_{2}$ in amniotic fluid and leukocytosis of the fetal membranes (70). However, at the doses employed, no significant changes in amniotic fluid or fetal circulating cytokine concentrations were observed.

\section{TAK1 inhibitors}

The TAK1 kinase complex is unique to the TLR-mediated activation pathway and offers an excellent pharmacological target within the p38 MAPK and NF- $\kappa$ B pro-inflammatory signaling cascades to block premature activation of labor, without the downstream effects of IKK inhibition on constitutive NF- $\kappa \mathrm{B}$ activity (Figure 1, red circle at position 2). The upstream location of TAK1 also suggests that blockade of activity is likely to exert broadspectrum anti-inflammatory effects against the range of microbes and stimuli associated with IUI and inflammation. Gene deletion of TAK1 impairs IKK and NF- $\mathrm{B}$ activity, subsequently blocking pro-inflammatory cytokine release and expression (78). To date, availability of pharmacological TAK1 inhibitors is extremely limited; 5z-7-oxozeaenol (OxZnl), a resorcyclic acid lactone and selective inhibitor of TAK1 kinase, appears to be the most promising (79) and has been shown to inhibit pro-inflammatory mediator production in murine fibroblasts (72), primary cortical neurons (80), dermal fibroblasts (81), and ear swelling models (72). In an ovine model of LPS-induced chorioamnionitis, we recently demonstrated intra-amniotic treatment with OxZnl to reduce amniotic fluid levels of $\mathrm{PGE}_{2}$ and fetal membrane leukocyte infiltration (70), although intra-amniotic cytokine levels were not altered. Whilst these studies suggest that TAK1 kinase inhibitors might be an effective approach to prevent inflammation-induced PTL, caution is warranted as TAK1 is also involved in MAPK signaling which regulates cell function and signaling, including apoptosis and differentiation (74). Further studies are required to fully define the role of TAK1 in pregnancy and the clinical potential of TAK1 inhibitors.

\section{CONSIDERATIONS FOR THE CLINICAL TRANSLATION OF CSAIDS \\ MODE OF DRUG DELIVERY: SIDES EFFECTS AND EFFICACY}

In the context of PTB prevention, therapeutics should ideally eliminate the microorganism from the amniotic cavity, block the ensuing cytokine cascade that drives release of PGs and matrix metalloproteinases (MMPs), prevent the onset of PTL, and minimize risk of FIRS. While prophylactic antibiotic trials have not been overly encouraging, there have been some successes (82) and exciting new antibiotics such as solithromycin hold great promise (83). However, therapies that deal solely with the infection, without suppressing inflammation, are unlikely to achieve maximal benefit. The NAC clinical trial of Shahin et al. (39) demonstrated that maternal administration of CSAIDs (following antibiotics to treat bacterial vaginosis) could prevent PTB and improve neonatal outcomes, although it should be noted that the concentrations of
NAC achieved in amniotic fluid and fetal blood following maternal administration were not determined.

Given the wide range of genes controlled by NF- $\kappa \mathrm{B}$, the inhibition of NF- $\kappa$ B activation by CSAIDs could have unwanted side effects. Maternal administration may inhibit NF- $\mathrm{B}-$ dependent innate immune defenses, increasing susceptibility to infections (84). Caution is also warranted regarding the possibility of nonspecific fetal toxicity. Observations that p38 MAPK null mice are non-viable (57) highlight the need to investigate the safety and toxicity of p38 MAPK inhibitors during pregnancy. While there are no published studies on the teratogenic effects of IKK inhibitors, complete inhibition of NF- $\kappa \mathrm{B}$ activation by IKK $\beta$ gene deletion $\left(\mathrm{IKK} \beta^{-/-}\right)$resulted in embryonically lethal uncontrolled apoptosis in the liver of mice (64). Heterozygous IKK $\beta^{+/-}$embryos developed with normal livers, despite approximately $50 \%$ reduction in IKK $\beta$ activity, suggesting that modest inhibition in the fetus may be tolerated (64). The pharmacodynamic profile of TPCA-1 appears promising, and the lack of toxicity in vitro and in vivo suggests that this could be a useful therapeutic approach for the treatment of PTL. Intra-amniotic treatment with competitive ATP protein kinase inhibitors TPCA-1 (IKK $\beta$ inhibitor) and OxZnl (TAK1 inhibitor) in an ovine model of LPS-induced chorioamnionitis showed that the CSAIDs were well tolerated by the fetus, at least in the short-term, with no obvious changes in birth weight or fetal liver function observed (70). This suggests that modest reduction in the activity of upstream kinases IKK $\beta$ and TAK1 is unlikely to result in the complete suppression of NF$\kappa \mathrm{B}$ activity and non-specific toxicity. Clearly, such concerns are drug- and dose-dependent, requiring extensive and longer-term safety studies before clinical introduction.

Alternatively, it is possible to deliver anti-inflammatory agents directly to the amniotic cavity via ultrasound guided intraamniotic injection. This route will likely enhance efficacy by delivering the minimal effective dose to target tissues and minimizing unintended exposures and side effects. Depending on the compound, delayed clearance from the amniotic cavity may in fact enhance efficacy and allow single-dose therapy. Recently, we reported that the anti-inflammatory effects of TPCA-1 and SB239063 administered to the amniotic face in a human fetal membrane model were primarily restricted to the fetal compartment, suggesting a lack of trans-membrane transfer (38). The potential benefits of amniotic drug delivery must always be counterbalanced by an assessment of the risks. The procedureassociated risk of spontaneous miscarriage following second trimester amniocentesis is low, with a recent large study finding a non-significant $0.6 \%$ increase in miscarriage compared to controls over a 15-year period (85). How this compares to the risks of a third trimester intra-amniotic injection is not known, although the risks at later gestations are likely to be lower than at 12-20 weeks. Nevertheless, it would be prudent that intra-amniotic treatment be given selectively to women in whom a significant benefit from CSAID therapy can be expected.

\section{IDENTIFICATION OF WOMEN AT RISK: SHORT CERVIX AND INFLAMMATION}

Intrauterine infection is often chronic and usually asymptomatic until the presentation of PTL, at which time it is often too late to 
treat and the fetus has been irreversibly exposed (86). The early identification of women at high risk of adverse pregnancy outcome associated with IUI, before the presentation of clinical symptoms, is challenging but also key for the successful prevention of PTB and improvement of neonatal outcomes. Analysis of amniotic fluid/cervicovaginal fluid cytokine levels or microbial status have been explored to identify women at an elevated risk of PTB (87), but have lacked specificity and/or sensitivity. Sonographic studies have reported that a short cervix (cervical length $\leq 25 \mathrm{~mm}$ ) is associated with intra-amniotic inflammation, and patients with this condition are at increased risk of adverse pregnancy outcome $(88,89)$. Gomez et al. (90) reported that women with a cervical length of $\leq 15 \mathrm{~mm}$ between 22 and 30 weeks of gestation have a higher rate of microbial invasion of the amniotic cavity (43 vs. $3.9 \% ; p<0.05)$, and were more likely to deliver spontaneously before 35 weeks of gestation ( 66.7 vs. $13.5 \%$; $p<0.01)$. These studies suggest that assessing sonographic cervical length may be a useful predictor of risk of microbial invasion of the amniotic cavity and intra-amniotic inflammation (89).

\section{SUMMARY AND CONCLUSION}

Infection and inflammation is the leading cause of PTB, but antenatal antibiotic treatment has had limited success at preventing PTB or improving neonatal outcome $(30,91)$. Newer macrolide antibiotics such as solithromycin, with greater efficacy and better trans-placental passage, may prove in time to be more effective $(83,92)$. We propose that a combination of anti-inflammatory therapy and effective antibiotics will be required to combat IUI and reduce the associated inflammatory responses leading to PTL and adverse fetal sequelae. Intra-amniotic delivery offers significant advantages in terms of dose reduction, localized site of action, and reduction in potential side effects. CSAIDs, novel compounds that specifically target cytokine signaling pathways, have antiinflammatory actions in both human fetal membranes in vitro and animal models of IUI. These compounds have the potential to be safer and more effective than less selective inhibitors as they target key molecules involved in the pro-inflammatory signaling cascades that prematurely trigger labor. Issues regarding maternal and fetal toxicity, mode of drug delivery, off-target side effects, and appropriate identification of women requiring treatment remain to be addressed. Based on our current appreciation of the importance of IUI and inflammation in the etiology of PTB, the identification and treatment of pregnant women at risk of IUI with effective cytokine signaling inhibitors holds great promise for the prevention of PTB and improvement of neonatal outcomes.

\section{ACKNOWLEDGMENTS}

The funding support of the Women and Infants Research Foundation (WIRF), and the National Health and Medical Research Council (NHMRC) of Australia (grant \#APP1024467) are gratefully acknowledged.

\section{SUPPLEMENTARY MATERIAL}

The Supplementary Material for this article can be found online at http://journal.frontiersin.org/article/10.3389/fimmu.2015.00166

\section{REFERENCES}

1. Chang HH, Larson J, Blencowe H, Spong CY, Howson CP, CairnsSmith S, et al. Preventing preterm births: analysis of trends and potential reductions with interventions in 39 countries with very high human development index. Lancet (2013) 381(9862):223-34. doi:10.1016/S0140-6736(12) 61856-X

2. Goldenberg RL, Culhane JF, Iams JD, Romero R. Epidemiology and causes of preterm birth. Lancet (2008) 371(9606):75-84. doi:10.1016/S0140-6736(08) 60074-4

3. Blencowe H, Cousens S, Oestergaard MZ, Chou D, Moller AB, Narwal R, et al. National, regional, and worldwide estimates of preterm birth rates in the year 2010 with time trends since 1990 for selected countries: a systematic analysis and implications. Lancet (2012) 379(9832):2162-72. doi:10.1016/S0140-6736(12) 60820-4

4. Romero R, Espinoza J, Kusanovic JP, Gotsch F, Hassan S, Erez O, et al. The preterm parturition syndrome. BJOG (2006) 113(Suppl 3):17-42. doi:10.1111/ j.1471-0528.2006.01120.x

5. Dando SJ, Nitsos I, Polglase GR, Newnham JP, Jobe AH, Knox CL. Ureaplasma parvum undergoes selection in utero resulting in genetically diverse isolates colonizing the chorioamnion of fetal sheep. Biol Reprod (2014) 90(2):27. doi:10.1095/biolreprod.113.113456

6. Goldenberg RL, Culhane JF, Iams JD, Romero R. Preterm birth 1 - epidemiology and causes of preterm birth. Lancet (2008) 371(9606):75-84. doi:10.1016/ S0140-6736(08)60074-4

7. DiGiulio DB, Romero R, Kusanovic JP, Gomez R, Kim CJ, Seok KS, et al. Prevalence and diversity of microbes in the amniotic fluid, the fetal inflammatory response, and pregnancy outcome in women with preterm pre-labor rupture of membranes. Am J Reprod Immunol (2010) 64(1):38-57. doi:10.1111/j.16000897.2010.00830.x

8. Rinaldi SF, Hutchinson JL, Rossi AG, Norman JE. Anti-inflammatory mediators as physiological and pharmacological regulators of parturition. Expert Rev Clin Immunol (2011) 7(5):675-96. doi:10.1586/eci.11.58

9. Galinsky R, Polglase GR, Hooper SB, Black MJ, Moss TJ. The consequences of chorioamnionitis: preterm birth and effects on development. J Pregnancy (2013) 2013:412831. doi:10.1155/2013/412831

10. Gomez R, Romero R, Ghezzi F, Yoon BH, Mazor M, Berry SM. The fetal inflammatory response syndrome. Am J Obstet Gynecol (1998) 179(1):194-202. doi:10.1016/S0002-9378(98)70272-8

11. Hassan SS, Romero R, Vidyadhari D, Fusey S, Baxter JK, Khandelwal M, et al. Vaginal progesterone reduces the rate of preterm birth in women with a sonographic short cervix: a multicenter, randomized, double-blind, placebocontrolled trial. Ultrasound Obstet Gynecol (2011) 38(1):18-31. doi:10.1002/ uog. 9017

12. Keelan JA. Pharmacological inhibition of inflammatory pathways for the prevention of preterm birth. J Reprod Immunol (2011) 88(2):176-84. doi:10.1016/ j.jri.2010.11.003

13. Romero R, Gómez R, Chaiworapongsa T, Conoscenti G, Cheol Kim J, Mee Kim Y. The role of infection in preterm labour and delivery. Paediatr Perinat Epidemiol (2001) 15:41-56. doi:10.1046/j.1365-3016.2001.00007.x

14. Romero R, Espinoza J, Goncalves LF, Kusanovic JP, Friel LA, Nien JK. Inflammation in preterm and term labour and delivery. Semin Fetal Neonatal Med (2006) 11(5):317-26. doi:10.1016/j.siny.2006.05.001

15. Lockwood CJ. Predicting premature delivery - no easy task. N Engl J Med (2002) 346(4):282-4. doi:10.1056/NEJM200201243460412

16. Czikk MJ, McCarthy FP, Murphy KE. Chorioamnionitis: from pathogenesis to treatment. Clin Microbiol Infect (2011) 17(9):1304-11. doi:10.1111/j.1469-0691. 2011.03574.x

17. Pappas A, Kendrick DE, Shankaran S, Stoll BJ, Bell EF, Laptook AR, et al. Chorioamnionitis and early childhood outcomes among extremely lowgestational-age neonates. JAMA Pediatr (2014) 168(2):137-47. doi:10.1001/ jamapediatrics.2013.4248

18. Romero R, Espinoza J, Goncalves LF, Kusanovic JP, Friel L, Hassan S. The role of inflammation and infection in preterm birth. Semin Reprod Med (2007) 25(1):21-39. doi:10.1055/s-2006-956773

19. Combs CA, Gravett M, Garite TJ, Hickok DE, Lapidus J, Porreco R, et al. Amniotic fluid infection, inflammation, and colonization in preterm labor with intact membranes. Am J Obstet Gynecol (2014) 210(2):.e1-125. doi:10.1016/j.ajog. 2013.11 .032 
20. Keelan JA, Blumenstein M, Helliwell RJ, Sato TA, Marvin KW, Mitchell MD. Cytokines, prostaglandins and parturition - a review. Placenta (2003) 24(Suppl A):S33-46. doi:10.1053/plac.2002.0948

21. Kemp MW, Saito M, Newnham JP, Nitsos I, Okamura K, Kallapur SG. Preterm birth, infection, and inflammation advances from the study of animal models. Reprod Sci (2010) 17(7):619-28. doi:10.1177/1933719110373148

22. Ratajczak CK, Muglia LJ. Insights into parturition biology from genetically altered mice. Pediatr Res (2008) 64(6):581-9. doi:10.1203/PDR. 0b013e31818718d2

23. Kawai T, Akira S. The role of pattern-recognition receptors in innate immunity: update on toll-like receptors. Nat Immunol (2010) 11(5):373-84. doi:10.1038/ ni. 1863

24. Takeda K, Akira S. Toll-like receptors in innate immunity. Int Immunol (2005) 17(1):1-14. doi:10.1093/intimm/dxh186

25. Oeckinghaus A, Ghosh S. The NF-kappaB family of transcription factors and its regulation. Cold Spring Harb Perspect Biol (2009) 1(4):a000034. doi:10.1101/ cshperspect.a000034

26. Hayden MS, Ghosh S. Signaling to NF-kappaB. Genes Dev (2004) 18(18):2195-224. doi:10.1101/gad.1228704

27. Schindler JF, Monahan JB, Smith WG. p38 pathway kinases as anti-inflammatory drug targets. J Dent Res (2007) 86(9):800-11. doi:10.1177/154405910708600902

28. Lappas M, Permezel M, Rice GE. Mitogen-activated protein kinase proteins regulate LPS-stimulated release of pro-inflammatory cytokines and prostaglandins from human gestational tissues. Placenta (2007) 28(8-9):936-45. doi:10.1016/ j.placenta.2007.02.009

29. Flenady V, Hawley G, Stock OM, Kenyon S, Badawi N. Prophylactic antibiotics for inhibiting preterm labour with intact membranes. Cochrane Database Syst $\operatorname{Rev}$ (2013) (12):CD000246. doi:10.1002/14651858.CD000246.pub2

30. Kenyon S, Boulvain M, Neilson JP. Antibiotics for preterm rupture of membranes. Cochrane Database Syst Rev (2010) (8):CD001058. doi:10.1002/ 14651858.CD001058.pub2

31. King JF, Flenady V, Cole S, Thornton S. Cyclo-oxygenase (COX) inhibitors for treating preterm labour. Cochrane Database Syst Rev (2005) (2):CD001992. doi:10.1002/14651858.CD001992.pub2

32. Haas DM, Imperiale TF, Kirkpatrick PR, Klein RW, Zollinger TW, Golichowski AM. Tocolytic therapy: a meta-analysis and decision analysis. Obstet Gynecol (2009) 113(3):585-94. doi:10.1097/AOG.0b013e318199924a

33. Loudon JA, Groom KM, Bennett PR. Prostaglandin inhibitors in preterm labour. Best Pract Res Clin Obstet Gynaecol (2003) 17(5):731-44. doi:10.1016/S15216934(03)00047-6

34. Zafarullah M, Li W, Sylvester J, Ahmad M. Molecular mechanisms of Nacetylcysteine actions. Cell Mol Life Sci (2003) 60(1):6-20. doi:10.1007/ s000180300001

35. Millea PJ. N-acetylcysteine: multiple clinical applications. Am Fam Physician (2009) 80(3):265-9.

36. Chang EY, Zhang J, Sullivan S, Newman R, Singh I. N-acetylcysteine attenuates the maternal and fetal proinflammatory response to intrauterine LPS injection in an animal model for preterm birth and brain injury. J Matern Fetal Neonatal Med (2011) 24(5):732-40. doi:10.3109/14767058.2010.528089

37. Lappas M, Permezel M, Rice GE. N-Acetyl-cysteine inhibits phospholipid metabolism, proinflammatory cytokine release, protease activity, and nuclear factor-kappaB deoxyribonucleic acid-binding activity in human fetal membranes in vitro. J Clin Endocrinol Metab (2003) 88(4):1723-9. doi:10.1210/jc. 2002-021677

38. Stinson LF, Ireland DJ, Kemp MW, Payne MS, Stock SJ, Newnham JP, et al. Effects of cytokine-suppressive anti-inflammatory drugs on inflammatory activation in ex vivo human and ovine fetal membranes. Reproduction (2014) 147(3):313-20. doi:10.1530/REP-13-0576

39. Shahin AY, Hassanin IM, Ismail AM, Kruessel JS, Hirchenhain J. Effect of oral Nacetyl cysteine on recurrent preterm labor following treatment for bacterial vaginosis. Int J Gynaecol Obstet (2009) 104(1):44-8. doi:10.1016/j.ijgo.2008.08.026

40. Weber CK, Liptay S, Wirth T, Adler G, Schmid RM. Suppression of NF-kappaB activity by sulfasalazine is mediated by direct inhibition of IkappaB kinases alpha and beta. Gastroenterology (2000) 119(5):1209-18. doi:10.1053/gast.2000.19458

41. Rahimi R, Nikfar S, Rezaie A, Abdollahi M. Pregnancy outcome in women with inflammatory bowel disease following exposure to 5-aminosalicylic acid drugs: a meta-analysis. Reprod Toxicol (2008) 25(2):271-5. doi:10.1016/j.reprotox.2007. 11.010
42. Keelan JA, Khan S, Yosaatmadja F, Mitchell MD. Prevention of inflammatory activation of human gestational membranes in an ex vivo model using a pharmacological NF-kappaB inhibitor. J Immunol (2009) 183(8):5270-8. doi:10.4049/jimmunol.0802660

43. Nath CA, Ananth CV, Smulian JC, Peltier MR. Can sulfasalazine prevent infection-mediated pre-term birth in a murine model? Am J Reprod Immunol (2010) 63(2):144-9. doi:10.1111/j.1600-0897.2009.00773.x

44. Adams Waldorf KM, Persing D, Novy MJ, Sadowsky DW, Gravett MG. Pretreatment with toll-like receptor 4 antagonist inhibits lipopolysaccharide-induced preterm uterine contractility, cytokines, and prostaglandins in rhesus monkeys. Reprod Sci (2008) 15(2):121-7. doi:10.1177/1933719107310992

45. Li L, Kang J, Lei W. Role of Toll-like receptor 4 in inflammation-induced preterm delivery. Mol Hum Reprod (2010) 16(4):267-72. doi:10.1093/molehr/gap106

46. Hawkins LD, Christ WJ, Rossignol DP. Inhibition of endotoxin response by synthetic TLR4 antagonists. Curr Top Med Chem (2004) 4(11):1147-71. doi:10.2174/1568026043388123

47. Matsunaga N, Tsuchimori N, Matsumoto T, Ii M. TAK-242 (resatorvid), a smallmolecule inhibitor of Toll-like receptor (TLR) 4 signaling, binds selectively to TLR4 and interferes with interactions between TLR4 and its adaptor molecules. Mol Pharmacol (2011) 79(1):34-41. doi:10.1124/mol.110.068064

48. Fidel PL Jr, Romero R, Cutright J, Wolf N, Gomez R, Araneda H, et al. Treatment with the interleukin-I receptor antagonist and soluble tumor necrosis factor receptor Fc fusion protein does not prevent endotoxin-induced preterm parturition in mice. J Soc Gynecol Investig (1997) 4(1):22-6. doi:10.1016/S10715576(96)00060-3

49. Holmgren C, Esplin MS, Hamblin S, Molenda M, Simonsen S, Silver R. Evaluation of the use of anti-TNF-alpha in an LPS-induced murine model. J Reprod Immunol (2008) 78(2):134-9. doi:10.1016/j.jri.2007.11.003

50. El Mourabet M, El-Hachem S, Harrison JR, Binion DG. Anti-TNF antibody therapy for inflammatory bowel disease during pregnancy: a clinical review. Curr Drug Targets (2010) 11(2):234-41. doi:10.2174/138945010790309885

51. Geiler J, Buch M, McDermott MF. Anti-TNF treatment in rheumatoid arthritis. Curr Pharm Des (2011) 17(29):3141-54. doi:10.2174/138161211798157658

52. Djokanovic N, Klieger-Grossmann C, Pupco A, Koren G. Safety of infliximab use during pregnancy. Reprod Toxicol (2011) 32(1):93-7. doi:10.1016/j.reprotox. 2011.05.009

53. Nielsen OH, Loftus EV Jr, Jess T. Safety of TNF-alpha inhibitors during IBD pregnancy: a systematic review. BMC Med (2013) 11:174. doi:10.1186/17417015-11- 174

54. di Meglio P, Ianaro A, Ghosh S. Amelioration of acute inflammation by systemic administration of a cell-permeable peptide inhibitor of NF-kappaB activation. Arthritis Rheum (2005) 52(3):951-8. doi:10.1002/art.20960

55. Underwood DC, Osborn RR, Kotzer CJ, Adams JL, Lee JC, Webb EF, et al. SB 239063 , a potent p38 MAP kinase inhibitor, reduces inflammatory cytokine production, airways eosinophil infiltration, and persistence. J Pharmacol Exp Ther (2000) 293(1):281-8

56. Ward KW, Proksch JW, Azzarano LM, Salyers KL, McSurdy-Freed JE, Molnar TM, et al. SB-239063, a potent and selective inhibitor of p38 map kinase: preclinical pharmacokinetics and species-specific reversible isomerization. Pharm Res (2001) 18(9):1336-44. doi:10.1023/A:1013002414678

57. Kumar S, Boehm J, Lee JC. p38 MAP kinases: key signalling molecules as therapeutic targets for inflammatory diseases. Nat Rev Drug Discov (2003) 2(9):717-26. doi:10.1038/nrd1177

58. Perregaux DG, Dean D, Cronan M, Connelly P, Gabel CA. Inhibition of interleukin-1 beta production by SKF86002: evidence of two sites of in vitro activity and of a time and system dependence. Mol Pharmacol (1995) 48(3):433-42.

59. LaMarca HL, Dash PR, Vishnuthevan K, Harvey E, Sullivan DE, Morris CA, et al. Epidermal growth factor-stimulated extravillous cytotrophoblast motility is mediated by the activation of PI3-K, Akt and both p38 and p42/44 mitogen-activated protein kinases. Hum Reprod (2008) 23(8):1733-41. doi:10. 1093/humrep/den 178

60. Vaillancourt C, Lanoix D, Le Bellego F, Daoud G, Lafond J. Involvement of MAPK signalling in human villous trophoblast differentiation. Mini Rev Med Chem (2009) 9(8):962-73. doi:10.2174/138955709788681663

61. Force T, Kuida K, Namchuk M, Parang K, Kyriakis JM. Inhibitors of protein kinase signaling pathways: emerging therapies for cardiovascular disease. $\mathrm{Circu}$ lation (2004) 109(10):1196-205. doi:10.1161/01.CIR.0000118538.21306.A9 
62. Kim JH, Studer RK, Vo NV, Sowa GA, Kang JD. p38 MAPK inhibition selectively mitigates inflammatory mediators and VEGF production in AF cells cocultured with activated macrophage-like THP-1 cells. Osteoarthritis Cartilage (2009) 17(12):1662-9. doi:10.1016/j.joca.2009.06.004

63. Shibata W, Maeda S, Hikiba Y, Yanai A, Ohmae T, Sakamoto K, et al. Cutting edge: the IkappaB kinase (IKK) inhibitor, NEMO-binding domain peptide, blocks inflammatory injury in murine colitis. J Immunol (2007) 179(5):2681-5. doi:10.4049/jimmunol.179.5.2681

64. Li Z-W, Chu W, Hu Y, Delhase M, Deerinck T, Ellisman M, et al. The IKK $\beta$ subunit of IкB kinase (IKK) is essential for nuclear factor $\kappa \mathrm{B}$ activation and prevention of apoptosis. J Exp Med (1999) 189(11):1839-45. doi:10.1084/jem. 189.11.1839

65. Kwok BH, Koh B, Ndubuisi MI, Elofsson M, Crews CM. The anti-inflammatory natural product parthenolide from the medicinal herb feverfew directly binds to and inhibits IkappaB kinase. Chem Biol (2001) 8(8):759-66. doi:10.1016/S10745521(01)00049-7

66. De Silva D, Mitchell MD, Keelan JA. Inhibition of choriodecidual cytokine production and inflammatory gene expression by selective I-kappaB kinase (IKK) inhibitors. Br J Pharmacol (2010) 160(7):1808-22. doi:10.1111/j.1476-5381. 2010.00839.x

67. Smolinski AT, Pestka JJ. Modulation of lipopolysaccharide-induced proinflammatory cytokine production in vitro and in vivo by the herbal constituents apigenin (chamomile), ginsenoside Rbl (ginseng) and parthenolide (feverfew). Food Chem Toxicol (2003) 41(10):1381-90. doi:10.1016/S02786915(03)00146-7

68. Kiuchi H, Takao T, Yamamoto K, Nakayama J, Miyagawa Y, Tsujimura A, et al. Sesquiterpene lactone parthenolide ameliorates bladder inflammation and bladder overactivity in cyclophosphamide induced rat cystitis model by inhibiting nuclear factor- $\mathrm{B}$ phosphorylation. J Urol (2009) 181(5):2339-48. doi:10.1016/S0022-5347(09)60672-8

69. Podolin PL, Callahan JF, Bolognese BJ, Li YH, Carlson K, Davis TG, et al. Attenuation of murine collagen-induced arthritis by a novel, potent, selective small molecule inhibitor of IkappaB Kinase 2, TPCA-1 (2-[(aminocarbonyl)amino]5-(4-fluorophenyl)-3-thiophenecarboxamide), occurs via reduction of proinflammatory cytokines and antigen-induced T cell Proliferation. J Pharmacol Exp Ther (2005) 312(1):373-81.

70. Ireland DJ, Kemp MW, Miura Y, Saito M, Newnham JP, Keelan JA. Intraamniotic pharmacological blockade of inflammatory signalling pathways in an ovine chorioamnionitis mode. Mol Hum Reprod (2015). doi:10.1093/molehr/ gav005

71. Kondo Y, Fukuda K, Adachi T, Nishida T. Inhibition by a selective IkappaB kinase2 inhibitor of interleukin-1-induced collagen degradation by corneal fibroblasts in three-dimensional culture. Invest Ophthalmol Vis Sci (2008) 49(11):4850-7. doi:10.1167/iovs.08-1897

72. Ninomiya-Tsuji J, Kajino T, Ono K, Ohtomo T, Matsumoto M, Shiina $M$, et al. A resorcylic acid lactone, 5Z-7-oxozeaenol, prevents inflammation by inhibiting the catalytic activity of TAK1 MAPK kinase. J Biol Chem (2003) 278(20):18485-90. doi:10.1074/jbc.M207453200

73. Song Z, Zhu X, Jin R, Wang C, Yan J, Zheng Q, et al. Roles of the kinase TAK1 in CD40-mediated effects on vascular oxidative stress and neointima formation after vascular injury. PLoS One (2014) 9(7):e101671. doi:10.1371/journal.pone. 0101671

74. Zhang W, Liu HT. MAPK signal pathways in the regulation of cell proliferation in mammalian cells. Cell Res (2002) 12(1):9-18. doi:10.1038/sj. cr.7290105

75. Sullivan MHF, Alvi SA, Brown NL, Elder MG, Bennett PR. The effects of a cytokine suppressive anti-inflammatory drug on the output of prostaglandin E2 and interleukin- $1 \beta$ from human fetal membranes. Mol Hum Reprod (2002) 8(3):281-5. doi:10.1093/molehr/8.3.281

76. May MJ, Marienfeld RB, Ghosh S. Characterization of the Ikappa B-kinase NEMO binding domain. J Biol Chem (2002) 277(48):45992-6000. doi:10.1074/ jbc.M206494200

77. May MJ, D’Acquisto F, Madge LA, Glöckner J, Pober JS, Ghosh S. Selective inhibition of NF- $\kappa \mathrm{B}$ activation by a peptide that blocks the interaction of NEMO with the IкB kinase complex. Science (2000) 289(5484):1550-4. doi:10.1126/science.289.5484.1550
78. Sato S, Sanjo H, Takeda K, Ninomiya-Tsuji J, Yamamoto M, Kawai T, et al. Essential function for the kinase TAK1 in innate and adaptive immune responses. Nat Immunol (2005) 6(11):1087-95. doi:10.1038/ni1255

79. Wu J, Powell F, Larsen NA, Lai Z, Byth KF, Read J, et al. Mechanism and in vitro pharmacology of TAK1 inhibition by (5Z)-7-Oxozeaenol. ACS Chem Biol (2013) 8(3):643-50. doi:10.1021/cb3005897

80. Neubert M, Ridder DA, Bargiotas P, Akira S, Schwaninger M. Acute inhibition of TAK1 protects against neuronal death in cerebral ischemia. Cell Death Differ (2011) 18(9):1521-30. doi:10.1038/cdd.2011.29

81. Acuna UM, Wittwer J, Ayers S, Pearce CJ, Oberlies NH, EJ DEB. Effects of (5Z)7-oxozeaenol on the oxidative pathway of cancer cells. Anticancer Res (2012) 32(7):2665-71.

82. Lamont RF, Sawant SR. Infection in the prediction and antibiotics in the prevention of spontaneous preterm labour and preterm birth. Minerva Ginecol (2005) 57(4):423-33.

83. Keelan JA, Kemp MW, Payne MS, Johnson D, Stock SJ, Saito M, et al. Maternal administration of solithromycin, a new, potent, broad-spectrum fluoroketolide antibiotic, achieves fetal and intra-amniotic antimicrobial protection in a pregnant sheep model. Antimicrob Agents Chemother (2014) 58(1):447-54. doi:10.1128/AAC.01743-13

84. Lawrence T. The nuclear factor NF-kappaB pathway in inflammation. Cold Spring Harbor Perspect Biol (2009) 1(6):a001651. doi:10.1101/cshperspect. a001651

85. Theodora M, Antsaklis A, Blanas K, Antsaklis P, Daskalakis G, Sindos M, et al. Risk for fetal loss and prematurity after 12,413 second trimester amniocenteses in a single center. J Perinat Med (2014). doi:10.1515/jpm-2014-0236

86. Goncalves LF, Chaiworapongsa T, Romero R. Intrauterine infection and prematurity. Ment Retard Dev Disabil Res Rev (2002) 8(1):3-13. doi:10.1002/mrdd. 10008

87. Menon R, Torloni MR, Voltolini C, Torricelli M, Merialdi M, Betrán AP, et al. Biomarkers of spontaneous preterm birth: an overview of the literature in the last four decades. Reprod Sci (2011) 18(11):1046-70. doi:10.1177/ 1933719111415548

88. Hassan S, Romero R, Hendler I, Gomez R, Khalek N, Espinoza J, et al. A sonographic short cervix as the only clinical manifestation of intra-amniotic infection. J Perinat Med (2006) 34(1):13-9. doi:10.1515/JPM.2006.002

89. Romero R, Miranda J, Chaiworapongsa T, Chaemsaithong P, Gotsch F, Dong $Z$, et al. Sterile intra-amniotic inflammation in asymptomatic patients with a sonographic short cervix: prevalence and clinical significance. J Matern Fetal Neonatal Med (2014):1-52. doi:10.3109/14767058.2014.958463

90. Gomez R, Romero R, Nien JK, Chaiworapongsa T, Medina L, Kim YM, et al. A short cervix in women with preterm labor and intact membranes: a risk factor for microbial invasion of the amniotic cavity. Am J Obstet Gynecol (2005) 192(3):678-89. doi:10.1016/j.ajog.2004.10.624

91. Brocklehurst P, Gordon A, Heatley E, Milan SJ. Antibiotics for treating bacterial vaginosis in pregnancy. Cochrane Database Syst Rev (2013) (1):CD000262. doi:10.1002/14651858.CD000262.pub4

92. Keelan JA, Pugazhenthi K. Trans-placental passage and anti-inflammatory effects of solithromycin in the human placenta. Placenta (2014) 35(12):1043-8.

Conflict of Interest Statement: The authors declare that the research was conducted in the absence of any commercial or financial relationships that could be construed as a potential conflict of interest.

Received: 05 February 2015; accepted: 26 March 2015; published online: 20 April 2015. Citation: Ng PY, Ireland DJ and Keelan JA (2015) Drugs to block cytokine signaling for the prevention and treatment of inflammation-induced preterm birth. Front. Immunol. 6:166. doi: 10.3389/fimmu.2015.00166

This article was submitted to Inflammation, a section of the journal Frontiers in Immunology.

Copyright (c) $2015 \mathrm{Ng}$, Ireland and Keelan. This is an open-access article distributed under the terms of the Creative Commons Attribution License (CC BY). The use, distribution or reproduction in other forums is permitted, provided the original author(s) or licensor are credited and that the original publication in this journal is cited, in accordance with accepted academic practice. No use, distribution or reproduction is permitted which does not comply with these terms. 